\title{
EGFR and K-ras gene mutation status in squamous cell anal carcinoma: a role for concurrent radiation and EGFR inhibitors?
}

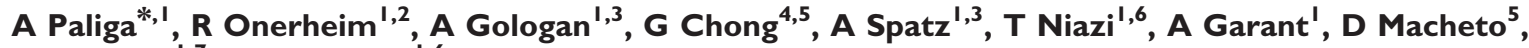 \\ T Alcindor ${ }^{1,7}$ and T Vuong ${ }^{1,6}$
}

'Faculty of Medicine, McGill University, Montreal, Quebec, Canada H3G IY6; ${ }^{2}$ St Mary's Hospital, Montreal, Quebec, Canada H3T IM5; ${ }^{3}$ Department of Pathology, Lady Davis Institute for Medical Research, Jewish General Hospital, Montreal, Quebec, Canada H3T IE2; ${ }^{4}$ Department of Genetics, McGill University, Montreal, Quebec, Canada H3G IY6; ${ }^{5}$ Molecular Pathology Unit, Department Of Pathology, Jewish General Hospital, Montreal, Quebec, Canada H3T IE2; ${ }^{6}$ Department of Oncology, Division of Radiation Oncology, Segal Cancer Centre, Jewish General Hospital, Montreal, Quebec, Canada H3T IE2; ' Department of Oncology, Montreal General Hospital, Montreal, Quebec, Canada H3H 2 R9

BACKGROUND: There is a growing appreciation for radio-sensitiser use in multi-modal cancer treatment models. Squamous cell anal carcinoma (SCAC) is a rare gastrointestinal tumour traditionally treated with concurrent chemotherapy and radiation. Cetuximab, an epidermal growth factor receptor (EGFR) inhibitor, has demonstrated significant efficacy when combined with radiation in squamous cell carcinoma of the head and neck (SccH\&N). We wanted to assess EGFR and Kirsten-ras (K-ras) status in SCAC to see whether it compares with SccH\&N.

METHODS: Over 90 SCAC paraffin-embedded biopsies were mounted onto a tissue microarray and were assessed for EGFR expression by immunohistochemistry. These samples were also assessed for the most frequently mutated K-ras and EGFR exons by high-resolution melting analysis.

RESULTS: The EGFR was present in over $90 \%$ of samples tested. The K-ras and EGFR mutations were absent in all samples tested, although a synonymous single-nucleotide polymorphism was found in 3 out of 89 samples tested for EGFR exon 19.

CONCLUSION: The low rate of K-ras and EGFR mutations, coupled with the high surface expression of EGFR, suggests similarity in the EGFR signalling pathway between SCAC and ScCH\&N, and thus a potential role for EGFR inhibitors in SCAC. To our knowledge this is the largest cohort of invasive SCAC samples investigated for EGFR and K-ras mutations reported to date. British Journal of Cancer (2012) I 07, I864-1868. doi:I0.1038/bjc.20 I2.479 www.bjcancer.com

Published online 23 October 2012

(C) 2012 Cancer Research UK

Keywords: EGFR; anal carcinoma; immunohistochemistry; K-ras; high-resolution melting analysis

Squamous cell carcinoma of the anal canal (SCAC) is an epithelial cancer of the alimentary tract that is associated with HPV infection and is radiosensitive (Matczak, 2001). Treatment for the past four decades has involved concurrent fluorouracil/mitomycin and radiation therapy (Glynne-Jones and Mawdsley, 2008). Although effective, treatment is associated with significant morbidity: pancytopenia, severe diarrhoea and dermatitis. Furthermore, patients with progressive disease are left with limited and untested options. Hence, it is important that new treatment strategies be investigated.

In the past two decades a significant amount of research has been spurred by the concept of using tumour-specific biomolecules to increase response rates and decrease morbidity of current cancer treatment regimens (Ciardiello and Tortora, 2008). Furthermore, the more recent discovery that certain biomolecules can sensitise tumours to radiation therapy has opened the door to the field of molecular radiation biology/oncology (Zaidi et al, 2009). To date, the most successful example of radiosensitisation by a biomolecule is that of Cetuximab. Recently, the US Food and

*Correspondence: Dr A Paliga; E-mail: aleks.p@gmail.com

Received 27 July 2012; revised 25 September 2012; accepted 26 September 2012; published online 23 October 2012
Drug Administration approved the use of Cetuximab for the treatment of squamous cell carcinoma of the head and neck $(\mathrm{SccH} \& \mathrm{~N})$ in combination with radiation therapy (Ciardiello and Tortora, 2008).

Cetuximab (Erbitux/C225) is an IgG1 chimeric monoclonal antibody against epidermal growth factor receptor (EGFR). The EGFR (HER-1 or erbB1) is a member of the tyrosine kinase receptor family that also includes HER2 (erbB2), erbB3 and erbB4. It is believed that EGFR contributes to tumour development and progression through autocrine stimulation of cell proliferation (Matczak, 2001). The EGFR is overexpressed in many common epithelial cancers and it is associated with poor prognosis and treatment response (Nicholson et al, 2001; Ang et al, 2002).

Several tyrosine kinase activating EGFR mutations have been identified, the majority of which are associated with responsiveness to EGFR inhibition in non-small cell lung cancer (NSCLC) (Lynch et al, 2004). The two most common EGFR mutations, representing $85-90 \%$ of documented EGFR mutations, result from an in-frame deletion of 9-24 nucleotides centred around codons $746-750$ in exon 19 , or a point mutation at nucleotide 2573 (CTG to CGG) resulting in an arginine for leucine substitution at amino acid 858 (L858R) in exon 21 (Riely et al, 2006).

Kirsten-ras (K-ras), a small signalling G-protein downstream of $E G F R$, is necessary for EGFR signal transduction. Activating 
mutations of the K-ras gene have been strongly associated with decreased response to EGFR tyrosine kinase inhibitors in NSCLC (Eberhard et al, 2005), and decreased response to Cetuximab monotherapy in colorectal cancer (Karapetis et al, 2008). The $K$-ras mutations have also been implicated in tumour radioresistance (Bernhard et al, 2000). Mutations in codon 12 and 13 of exon 2 account for up to $99 \%$ of all $K$-ras mutations (Bos, 1989).

The EGFR wild-type expression and gene mutation status, as well as $K$-ras mutation status, has not been well investigated in a large anal carcinoma cohort. This study undertook the task to determine the EGFR expression as well as the K-ras and EGFR gene mutation status, in over 90 anal cancer biopsy samples from the Montreal area.

\section{METHODS}

\section{Acquisition of pathology blocks}

Following approval from our local ethics board, paraffinembedded squamous cell anal cancer biopsy and tumour specimens were collected from patients treated in the Montreal area between 1990 and 2010. Written informed consent was obtained from all patients before testing.

\section{DNA extraction}

Ninety five tissue-embedded paraffin blocks were cut into $4 \mu \mathrm{m}$ sections and stained with haematoxylin and eosin (H\&E) for tumour cell identification. Six blocks were excluded on pathology re-review because of non-typical features. Thus, 89 samples remained. Paraffin blocks with tumour dense areas were scraped, and DNA was extracted from the scrapings using the MagNA Pure Compact Nucleic Acid Isolation Kit I in the MagNA Pure Compact Instrument (Roche Diagnostics, Burgess Hill, UK), which eluted the purified DNA samples to $50 \mu \mathrm{l}$. The concentration and purity of each sample was assessed using a NanoDrop ND-1000 spectrophotometer (Thermo Scientific, Waltham, MA, USA). Samples were then diluted to $15 \mathrm{ng} \mu \mathrm{l}^{-1}$ DNA in TE buffer for analysis.

\section{High-resolution DNA melting}

The K-ras and EGFR exons 19 and 21 mutation status was determined using high-resolution melting analysis (HRMA) on PCR-amplified samples. The PCR was performed using Invitrogen HRMA Primers for K-ras (Carlsbad, CA, USA), EGFR exon 21 and EGFR exon 19 on a MJ Research PTC-200 Peltier Thermal cycler (Bio-Rad, Hercules, CA, USA) with 42 cycles ranging in temperature from 65 to $95{ }^{\circ} \mathrm{C}$. Briefly, the reaction mixture for HRMA included $3 \mu \mathrm{l}$ sterile water, $4 \mu \mathrm{l}$ LightScanner Master Mix (Idaho Technology, Salt Lake City, UT, USA), $1 \mu$ l LC green fluorescent dye, $0.2 \mu \mathrm{l} 1: 1 \mathrm{mix}$ of forward and reverse primer ( $25 \mu \mathrm{m}$ for $E G F R$ and $10 \mu \mathrm{m}$ for $K$-ras assays) and $2 \mu \mathrm{l}$ of $15 \mathrm{ng} \mu \mathrm{l}^{-1}$ DNA sample.

Samples that resembled the positive controls, or looked like outliers from the negative control, were checked by direct sequencing. A sample was deemed positive if its melting curve resembled the positive control or it landed outside of the wild-type spread.

The PCR for HRMA was performed on a Bio-Rad Hard Shell 96 microplate (Bio-Rad) and all samples were run in duplicate. Positive and negative controls consisted of lung or colorectal cancer samples known to either contain the sought after mutation ( $K$-ras codon 12 out of 13 mutation in exon 2, EGFR exon 19 in-frame deletion or EGFR exon 21 L858R mutation) or known to be wild-type. Two wells containing the PCR mix without DNA were run with each plate to control for contamination. Once PCR was finished, the microplate was loaded into the LightScanner Instrument (HR I 96 Idaho Technology) and the samples were melted and analysed as per the LightScanner Program.

Sample sequencing was done using Applied Biosystems' BigDye ReadyReaction Mix v1.1 (Foster City, CA, USA). Briefly, $2 \mu \mathrm{l}$ from each sample of interest was diluted in $70 \mu \mathrm{l}$ of sterile water. Samples were amplified by PCR; the products were elongated using a single primer (forward or reverse) as per the kit protocol. Following the PCR reaction, an AutoSeq G-50 Dye Terminator Removal Kit (GE Healthcare, Little Chalfont, UK) was used to remove excess ddNTPs. Samples were dried, $10 \mu \mathrm{l}$ of HiDi formamide was added to each sample, and then samples were subsequently loaded onto the ABI 3130 Genetic Analyzer (Applied Biosystems).

\section{Tissue microarray and immunohistochemistry}

An additional six cases obtained in 2009 and 2010 from the Montreal area were added to those initially obtained for testing with HRMA, and thus 95 tissue-embedded paraffin blocks were cut into $4 \mu \mathrm{m}$ sections and stained with $\mathrm{H} \& \mathrm{E}$ for tumour cell identification. Next, areas with tumour cells were marked on each H\&E slide, and from each case: one core of paraffin-embedded cancer tissue was taken. A tissue microarray (TMA) block consisting of 96 cores was constructed. The TMA was constructed using a Beecher Manual Array (Sun Prairie, WI, USA). Of the initial samples, only 87 had cancerous tissue in the paraffin block following tissue removal for DNA extraction. Eight cases were lost with TMA construction and cutting.

Table 1 details the characteristics of 79 patients whose samples were analysed by immunohistochemistry (IHC). Immunohistochemistry was performed at the Segal Cancer Centre Research Pathology Facility. Four micron formalin-fixed paraffin-embedded sections were cut, placed on SuperFrost/Plus slides (Thermo Fisher Scientific), and dried overnight. Sections were deparaffinised in xylene and rehydrated through graded alcohols to water. Sections were subjected to proteinase K (Sigma-Aldrich, St Louis, MO, USA) antigen retrieval for $5 \mathrm{~min}$ at $37^{\circ} \mathrm{C}$. The slides were then loaded onto the Discovery XT Autostainer (Ventana Medical System, Tucson, AZ, USA). All solutions used for automated IHC were from Ventana Medical System. The EGFR mab, clone SPM 341 (Catalogue No: 53449), was purchased from AnaSpec (Fremont, CA, USA). Negative control was performed by the omission of the primary antibody. The positive control for wild-type EGFR was human placental tissue. Immunostaining for EGFR was performed online using a heat protocol.

Sections were scored for staining intensity with conventional light microscopy under $\times 100$ and $\times 400$ magnification by two board-certified anatomic pathologists (RO and AG) blinded to sample identification. The immunostaining was evaluated in two ways: percentage of immunoreactive cells showing membrane staining, and the intensity of that staining graded 1-3 following the description and examples in the DAKO (Agilent Technologies, Santa Clara, CA, USA) monograph for EGFR staining in colorectal adenocarinoma. Any membrane staining was considered positive for wild-type EGFR, and cases with no membrane staining were scored 0 . A semi-quantitative combination score combining staining intensity with the percent of cells

Table I Patient characteristics of tested samples

\begin{tabular}{lcc}
\hline Characteristics & $\begin{array}{c}\text { No. of cases } \\
\text { for HRMA } \\
\text { (89 total) }\end{array}$ & $\begin{array}{c}\text { No. of cases } \\
\text { reported for IHC } \\
\text { (79 total) }\end{array}$ \\
\hline $\begin{array}{l}\text { Median age at diagnosis (range) } \\
\text { Sex: male }\end{array}$ & $59.5(37-88)$ & $59(37-88)$ \\
Histologic findings & $33(37 \%)$ & $29(37 \%)$ \\
Well-differentiated & & \\
Moderately differentiated & $8(9 \%)$ & $9(11 \%)$ \\
Poorly differentiated & $46(52 \%)$ & $41(52 \%)$ \\
Baseloid & $18(20 \%)$ & $14(18 \%)$ \\
\hline
\end{tabular}

Abbreviations: $\mathrm{HRMA}=$ high-resolution melting analysis; $\mathrm{HHC}=$ immunohistochemistry. 
staining gave a final score: just detectable or weak $(1+)$; moderate $(2+)$; strong/intense $(3+)$.

\section{RESULTS}

\section{High-resolution melting analysis}

The HRMA is an established technique for accurate, rapid and inexpensive screening of paraffin-embedded tissue samples for $K$-ras and EGFR mutations with $100 \%$ sensitivity and $90 \%$ specificity (Do et al, 2008). The technique relies on monitoring the melting curve of a PCR-amplified DNA samples that are saturated with a fluorescent dye. As the temperature rises, the DNA strands dissociate and fluorescent molecules are released. At a characteristic temperature single strands are formed and the fluorescence rapidly drops. The melting curve of a DNA product depends on its GC content, length, sequence and heterogeneity. Mutation scanning in particular is reliant on heteroduplex formation that distorts the shape of the melting curve as compared with a normalised curve of a wild-type reference (Reed et al, 2007).

Kirsten-ras exon 2 Zero out of 89 samples screened positive for $K$-ras mutations by HRMA. The results were verified by sequencing the positive control and one sample that was at the upper limit of wild-type spread: sample 68 . Sequencing confirmed this sample as negative (Figure 1A).

Epidermal growth factor receptor exon 19 Zero out of 89 samples tested by HRMA screened positive for an exon 19 deletion. One sample, sample 68, was an outlier that neither resembled the wildtype spread, nor the positive control. Sample 68 and the positive control were sequenced. Sample 68 was found to be wild-type, whereas the positive control was confirmed to have an in-frame deletion (Figure 1B).

Epidermal growth factor receptor exon 21 Three out of 89 samples (samples 5, 19, 53) tested positive by HRMA. Subsequently, samples 5, 19 and 53 were sequenced along with the positive control. The three samples $(5,19$ and 53) were found to all harbour the same single-nucleotide polymorphism (SNP) in position $r s 17290559$ (c.2508C > T(p.R836R)) (Figure 1C).

\section{Immunohistochemistry}

Epidermal growth factor receptor Ninety-one percent (72 out of 79 ) of samples stained at least weakly $(1+)$. Forty-nine percent $(39$ out of 79$)$ stained moderately $(2+)$ or strongly $(3+)$ (Table 2 and Figure 2).

\section{DISCUSSION}

Squamous cell anal carcinoma is an uncommon gastrointestinal tumour. To our knowledge, this is the largest cohort of SCAC samples investigated for EGFR and K-ras mutations reported to date. Although, IHC remains the best choice for routine clinical assessment of EGFR status, there is no standardised EGFR scoring system, so we chose to use the description and examples in the DAKO monograph for EGFR staining in colorectal adenocarinoma (Penault-Llorca et al, 2006). Using this scoring system, we found that $91 \%$ of our SCAC samples overexpressed EGFR, which is within the range of previous reports. In the earliest such study, Hui et al analysed 28 anal carcinomas for their immunoreactivity to EGFR and found that all but one sample was EGFR positive (Hui et al, 1999). Lê et al (2005) documented universally strong expression of EGFR in all 21 tested SCAC, whereas none overexpressed HER 2. Alvarez et al (2006) described expression in $55 \%$ of 38 SCAC tumour samples examined, among which two thirds had at
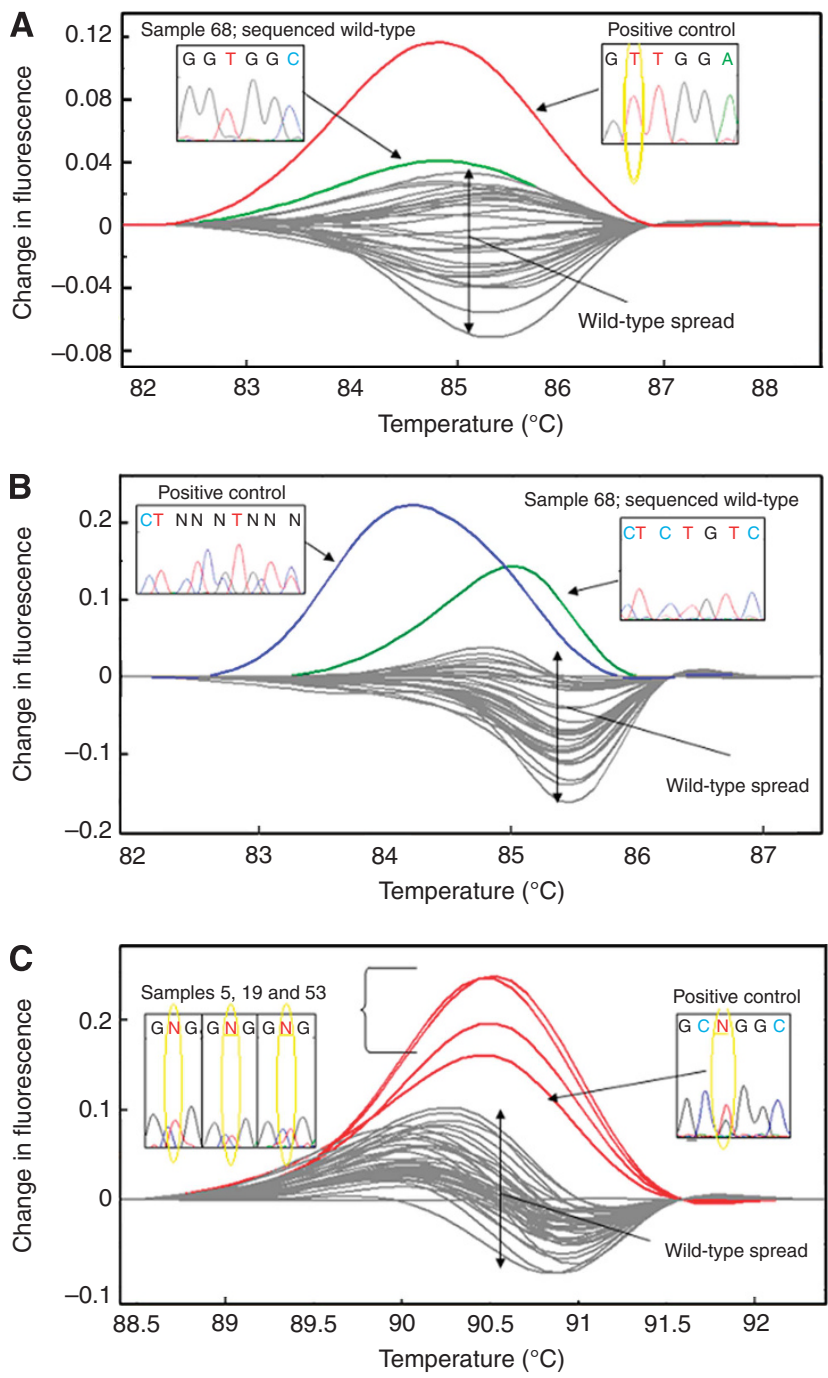

Figure I Representative plates from HRMA. Results from one of three 96-well plates done per exon is shown. Samples were run in duplicate, including the positive control, but only one well is shown per sample for graph clarity. The negative control is selected as baseline. Change in fluorescence is calculated by subtracting sample fluorescence from a negative control. (A) Kirsten-ras exon 2. The positive control is shown to be mutated in codon 12 out of 13, whereas sample 68 demonstrates the wild-type sequence in this position. (B) Epidermal growth factor receptor exon 19. The positive control is shown to have an in-frame deletion at base I 12, whereas sample 68 is shown to have the wild-type sequence at this same position. (C) Epidermal growth factor receptor exon 21 . The positive control is shown to have a CTG to CGG mutation. Samples 5, 19 and 53 are shown to harbour a GTG to GCG single polymorphism at position rs 17290559 (c.2508C > T[p.R836R]).

least moderate staining. The same monoclonal antibodies (EGFR, clone 31G7) from the same company were used for all three studies, but they used different antigen retrieval protocols. It is interesting to note that both Alvarez et al (2006) and Lê et al (2005) observed that tissue storage time has no affect on immunohistochemical detectability of EGFR if tissue blocks are used. Zampino et al (2009) used an EGFR pharmDX assay (DAKO, Agilent Technologies). Of their 12 tested samples, only 7 (58\%) stained with the Dako EGFR pharmDx Monoclonal Mouse Antibody. More recently, Walker et al (2009) found that $96 \%$ of 48 invasive SCAC displayed strong membrane immunoreactivity for EGFR using clone 3C6 from Ventana. They also tested in situ lesions as well as condyloma acuminata, and found that with progressive lesion severity, the 
Table 2 Assessment of EGFR antibody staining intensity

\begin{tabular}{lccccc}
\hline & \multicolumn{5}{c}{ Number of cases } \\
\cline { 2 - 6 } & $\begin{array}{c}\mathbf{0} \\
\text { Immunoreactivity (\%) }\end{array}$ & $\begin{array}{c}\text { I }+ \\
\text { (None) }\end{array}$ & $\begin{array}{c}\text { (Weak) } \\
\text { (Moderate) }\end{array}$ & $\begin{array}{c}3+ \\
\text { (Strong) }\end{array}$ & Total \\
\hline$<20$ & & 2 & 2 & 1 & 5 \\
$20-40$ & $1^{\text {a }}$ & 5 & 5 & 4 & 15 \\
$41-60$ & $1^{\text {a }}$ & 14 & 9 & 7 & 31 \\
$60-80$ & $1^{\text {a }}$ & 8 & 1 & 7 & 17 \\
$>80$ & $4^{\text {a }}$ & 4 & 1 & 2 & 11 \\
Total & 7 & 33 & 18 & 21 & 79 \\
\hline
\end{tabular}

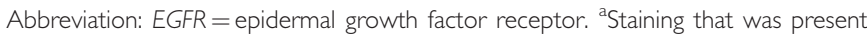
was cytoplasmic and not membranous, hence counted as absent.

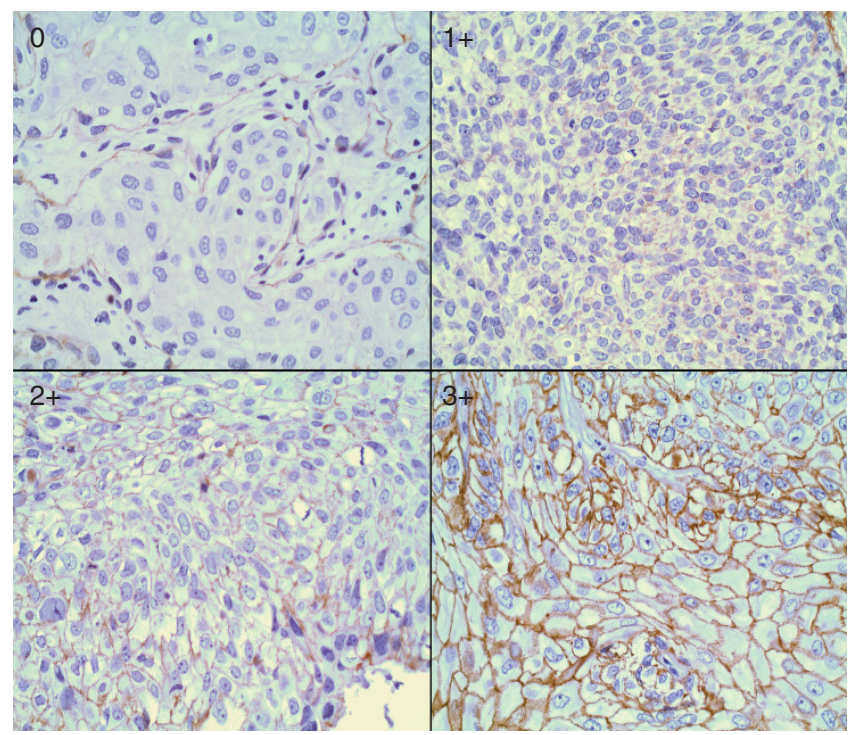

Figure 2 Epidermal growth factor receptor SCAC IHC. Representative photos at $\times 400$ magnification demonstrating $0,1+, 2+$ and $3+$ staining, respectively.

percentage of samples staining for EGFR increased. Finally, Van Damme et al (2010) looked at 43 cases of SCAC. Using clone 31G7 they found that about $84 \%$ ( 36 cases) showed immunoreactivity to $E G F R$, and among these, two thirds exhibited moderate $(2+)$ or strong $(3+)$ staining intensities. Overall, EGFR overexpression in SCAC appears to vary from 55 to $100 \%$ depending on the immunohistichemical techniques, antigen retrieval methods, antibodies and scoring systems. Our study, using clone SPM 341 from AnaSpec, demonstrated results in keeping with the literature and confirms that patients in the Montreal area have similar EGFR expression as those patients previously reported. It is noteworthy that all the samples that failed to show membranous EGFR staining did show some intracellular staining, suggesting possible intracellular stores. The significance of this is unknown as it has not been commented on by other authors. Similar to our cohort of samples, the vast majority of $\mathrm{SccH} \& \mathrm{~N}$ are also positive for EGFR overexpression by IHC (Ang et al, 2002; Thariat et al, 2012).

No K-ras mutations were detected in any of the SCAC samples screened against known positive controls. The K-ras mutations appear to be rare in squamous cell tumours as others reported low K-ras mutation rates in several epithelial tumours (Bos, 1989). Recently, Van Damme et al (2010) sequenced 30 anal cancer samples for $K$-ras mutation, and all samples were wild-type. Similarly, Zampino et al (2009) found that their 26 tested samples were wild-type $K$-ras as well.
All tested samples were negative for EGFR 19 mutations. One of our samples, sample 68, was an outlier from the wild-type spread, but it was found to harbour no mutation in the amplified exon when sequenced. This sample was likely a true false-positive in both the $K$-ras and EGFR exon 19 assays. False positives are well documented in HRMA secondary to degraded DNA from formalin-fixed paraffinembedded tissue (Do et al, 2008). The only other published paper to look at EGFR exon 19 mutations in SCAC found no mutations in their cohort of 30 samples (Van Damme et al, 2010).

Three samples tested positive by HRMA for EGFR exon 21 mutation and were confirmed to have a synonomous SNP by direct sequencing. Both the wild-type and mutated codon code for an arginine. The ability of the HRMA assay to identify the 1-bp change highlights the sensitivity of the technique and further validates its use. Within the limited published literature for EGFR mutations in SCAC, Van Damme et al (2010) also found no EGFR mutations in exon 21 in their 30 investigated samples.

The clinical significance of $K$-ras or EGFR mutation with regards to treatment with concurrent radiation and Cetuximab has not been established (Krause and Baumann, 2008). Radiation has been shown to stimulate EGFR signalling pathways, and repopulation of epithelial tumour cells after radiation exposure appears to be related to the activation and expression of EGFR (Peter et al, 1993; Schmidt-Ullrich et al, 1997; Petersen et al, 2003). Irradiation causes EGFR receptor internalisation and transport into the nucleus, binding of the receptor to the catalytic subunit of DNAprotein kinase, and subsequent repair of the lethal double-strand DNA breaks that result from radiation (Dittmann et al, 2005). Cetuximab inhibits EGFR activation in the absence and presence of radiation (Dittmann et al, 2005) and it is hypothesised that by preventing double-strand break repair, cancer cells are deprived of a key mechanism of radioresistance. Thus, when combined with radiotherapy, blockade of EGFR signalling could conceivably cause irreparable damage to the cancer cells, and result in cancer cure. Indeed, preliminary clinical trials suggest that effectiveness of radiation does increase if combined with anti-EGFR treatment. In a landmark phase III study by Bonner et al (2010), Cetuximab combined with radiotherapy $v s$ definitive radiotherapy alone at 5 years demonstrated significant benefits in median duration of overall survival (49 vs 29.3 months, $P=0.03$ ) in patients with SccH\&N. Furthermore, there have also been promising results in phase II trials with Cetuximab and concurrent radiation in stage III NSCLC (Jensen et al, 2011), and with chemoradiotherapy in locally advanced rectal cancer (Velenik et al, 2009). There are already a few reported cases of anal cancer patients being treated by EGFR inhibitor monotherapy or in combination with chemotherapy (Saif et al, 2011). Overall, there is hope in the field that EGFR inhibitors, when combined with current treatment regimens, will help improve survival in refractory anal cancer patients (Lim and Glynne-Jones, 2011).

Presently, there are no clinically established biological markers that can identify patients likely to be radiosensitised by EGFR inhibitors, but we do know that $\mathrm{SccH} \& \mathrm{~N}$ tumours express EGFR and lack both EGFR and K-ras mutations (Yarbrough et al, 1994; Temam et al, 2007). Our results confirm that SCAC overexpresses EGFR and lacks the most commonly described mutations in K-ras and EGFR. As SCAC is known to be a highly radiosensitive tumour, we support the introduction of clinical trials testing EGFR inhibitors, such as Cetuximab, with concurrent radiotherapy in SCAC.

\section{Conflict of interest}

The authors declare no conflict of interest.

\section{ACKNOWLEDGEMENTS}

We thank Naciba Benlimame for her help and guidance with the immunohistochemistry. 


\section{REFERENCES}

Alvarez G, Perry A, Tan BR, Wang HL (2006) Expression of epidermal growth factor receptor in squamous cell carcinomas of the anal canal is independent of gene amplification. Mod Pathol 19: 942-949

Ang KK, Berkey BA, Tu X, Zhang H-Z, Katz R, Hammond EH, Fu KK, Milas L (2002) Impact of epidermal growth factor receptor expression on survival and pattern of relapse in patients with advanced head and neck carcinoma. Cancer Res 62: 7350-7356

Bernhard EJ, Stanbridge EJ, Gupta S, Gupta AK, Soto D, Bakanauskas VJ, Cerniglia GJ, Muschel RJ, McKenna WG (2000) Direct evidence for the contribution of activated N-ras and K-ras oncogenes to increased intrinsic radiation resistance in human tumor cell lines. Cancer Res 60: 6597-6600

Bonner JA, Harari PM, Giralt J, Cohen RB, Jones CU, Sur RK, Raben D, Baselga J, Spencer SA, Zhu J, Youssoufian H, Rowinsky EK, Ang KK (2010) Radiotherapy plus cetuximab for locoregionally advanced head and neck cancer: 5-year survival data from a phase 3 randomised trial, and relation between cetuximab-induced rash and survival. Lancet Oncol 11: $21-28$

Bos JL (1989) ras oncogenes in human cancer: a review. Cancer Res 49: 4682-4689

Ciardiello F, Tortora G (2008) Drug therapy: EGFR antagonists in cancer treatment. $N$ Engl J Med 358: 1160-1174

Dittmann K, Mayer C, Fehrenbacher B, Schaller M, Raju U, Milas L, Chen DJ, Kehlbach R, Rodemann HP (2005) Radiation-induced epidermal growth factor receptor nuclear import is linked to activation of dnadependent protein kinase. J Biol Chem 280: 31182-31189

Do H, Krypuy M, Mitchell P, Fox S, Dobrovic A (2008) High resolution melting analysis for rapid and sensitive EGFR and KRAS mutation detection in formalin fixed paraffin embedded biopsies. BMC Cancer 8: 142

Eberhard DA, Johnson BE, Amler LC, Goddard AD, Heldens SL, Herbst RS, Ince WL, Janne PA, Januario T, Johnson DH, Klein P, Miller VA, Ostland MA, Ramies DA, Sebisanovic D, Stinson JA, Zhang YR, Seshagiri S, Hillan KJ (2005) Mutations in the epidermal growth factor receptor and in Kras are predictive and prognostic indicators in patients with nonsmall-cell lung cancer treated with chemotherapy alone and in combination with erlotinib. J Clin Oncol 23: 5900-5909

Glynne-Jones R, Mawdsley S (2008) Anal cancer: the end of the road for neoadjuvant chemoradiotherapy? J Clin Oncol 26: 3669-3671

Hui YZ, Noffsinger AE, Miller MA, Hurtubise P, Fenoglio-Preiser CM (1999) Strong growth factor receptor expression but not HER2/neu expression correlates with cell proliferation in anal canal carcinomas. Int J Surg Pathol 7: 193-203

Jensen AD, Munter MW, Bischoff HG, Haselmann R, Haberkorn U, Huber PE, Thomas M, Debus J, Herfarth KK (2011) Combined treatment of nonsmall cell lung cancer NSCLC stage III with intensity-modulated RT radiotherapy and cetuximab. Cancer 117: 2986-2994

Karapetis CS, Khambata-Ford S, Jonker DJ, O'Callaghan CJ, Tu D, Tebbutt NC, Simes RJ, Chalchal H, Shapiro JD, Robitaille S, Price TJ, Shepherd L, Au H-J, Langer C, Moore MJ, Zalcberg JR (2008) K-ras mutations and benefit from cetuximab in advanced colorectal cancer. N Engl J Med 359: 1757-1765

Krause M, Baumann M (2008) Clinical biomarkers of kinase activity: examples from EGFR inhibition trials. Cancer Metastasis Rev 27: 387-402

Lê LH, Chetty R, Moore MJ (2005) Epidermal growth factor receptor expression in anal canal carcinoma. Am J Clin Pathol 124: 20-23

Lim F, Glynne-Jones R (2011) Chemotherapy/chemoradiation in anal cancer: a systematic review. Cancer Treat Rev 37: 520-532

Lynch TJ, Bell DW, Sordella R, Gurubhagavatula S, Okimoto RA, Brannigan BW, Harris PL, Haserlat SM, Supko JG, Haluska FG, Louis DN, Christiani DC, Settleman J, Haber DA (2004) Activating mutations in the epidermal growth factor receptor underlying responsiveness of non-small-cell lung cancer to gefitinib. $N$ Engl J Med 350: 2129-2139
Matczak E (2001) Human papillomavirus infection: an emerging problem in anal and other squamous cell cancers. Gastroenterology 120: $1046-1048$

Nicholson RI, Gee JMW, Harper ME (2001) EGFR and cancer prognosis. Eur J Cancer 37: S9-S15

Penault-Llorca F, Cayre A, Arnould L, Bibeau F, Bralet MP, Rochaix P, Savary J, Sabourin JC (2006) Is there an immunohistochemical technique definitively valid in epidermal growth factor receptor assessment? Oncol Rep 16: 1173-1179

Peter RU, Beetz A, Ried C, Michel G, van Beuningen D, Ruzicka T (1993) Increased expression of the epidermal growth factor receptor in human epidermal keratinocytes after exposure to ionizing radiation. Radiat Res 136: $65-70$

Petersen C, Eicheler W, Frömmel A, Krause M, Balschukat S, Zips D, Baumann M (2003) Proliferation and micromilieu during fractionated irradiation of human $\mathrm{FaDu}$ squamous cell carcinoma in nude mice. Int J Radiat Biol 79: 469-477

Reed GH, Kent JO, Wittwer CT (2007) High-resolution DNA melting analysis for simple and efficient molecular diagnostics. Pharmacogenomics 8: 597-608

Riely GJ, Pao W, Pham D, Li AR, Rizvi N, Venkatraman ES, Zakowski MF, Kris MG, Ladanyi M, Miller VA (2006) Clinical course of patients with non-small cell lung cancer and epidermal growth factor receptor exon 19 and exon 21 mutations treated with gefitinib or erlotinib. Clin Cancer Res 12: $839-844$

Saif MW, Kontny E, Syrigos KN, Shahrokni A (2011) The role of EGFR inhibitors in the treatment of metastatic anal canal carcinoma: a case series. J Oncol 2011: 125467

Schmidt-Ullrich RK, Mikkelsen RB, Dent P, Todd DG, Valerie K, Kavanagh BD, Contessa JN, Rorrer WK, Chen PB (1997) Radiation-induced proliferation of the human A431 squamous carcinoma cells is dependent on EGFR tyrosine phosphorylation. Oncogene 15: 1191-1197

Temam S, Kawaguchi H, El-Naggar AK, Jelinek J, Tang H, Liu DD, Lang W, Issa J-P, Lee JJ, Mao L (2007) Epidermal growth factor receptor copy number alterations correlate with poor clinical outcome in patients with head and neck squamous cancer. J Clin Oncol 25: 2164-2170

Thariat J, Etienne-Grimaldi MC, Grall D, Bensadoun RJ, Cayre A, PenaultLlorca F, Veracini L, Francoual M, Formento JL, Dassonville O, De Raucourt D, Geoffrois L, Giraud P, Racadot S, Morinière S, Milano G, Van Obberghen-Schilling E (2012) Epidermal growth factor receptor protein detection in head and neck cancer patients: a many-faceted picture. Clin Cancer Res 18: 1313-1322

Van Damme N, Deron P, Van Roy N, Demetter P, Bols A, Van Dorpe J, Baert F, Van Laethem JL, Speleman F, Pauwels P, Peeters M (2010) Epidermal growth factor receptor and K-RAS status in two cohorts of squamous cell carcinomas. BMC Cancer 10: 189-197

Velenik V, Ocvirk J, Oblak I, Anderluh F (2009) A phase II study of cetuximab, capecitabine and radiotherapy in neoadjuvant treatment of patients with locally advanced resectable rectal cancer. Eur J Surg Oncol 36: $244-250$

Walker F, Abramowitz L, Benabderrahmane D, Duval X, Descatoire V, Hénin D, Lehy T, Aparicio T (2009) Growth factor receptor expression in anal squamous lesions: modifications associated with oncogenic human papillomavirus and human immunodeficiency virus. Hum Pathol 40: 1517-1527

Yarbrough WG, Shores C, Witsell DL, Weissler MC, Fidler ME, Gilmer TM (1994) ras mutations and expression in head and neck squamous cell carcinomas. Laryngoscope 104: 1337-1347

Zaidi SH, Huddart RA, Harrington KJ (2009) Novel targeted radiosensitisers in cancer treatment. Curr Drug Discov Technol 6: 103-134

Zampino M, Magni E, Sonzogni A, Renne G (2009) K-ras status in squamous cell anal carcinoma (SCC): it's time for target-oriented treatment? Cancer Chemother Pharmacol 65: 197-199

This work is published under the standard license to publish agreement. After 12 months the work will become freely available and the license terms will switch to a Creative Commons Attribution-NonCommercial-Share Alike 3.0 Unported License. 